\title{
Theranostic Concepts: More Than Just a Fashion Trend-Introduction and Overview
}

\author{
Ken Herrmann ${ }^{1,2}$, Steven M. Larson ${ }^{3}$, and Wolfgang A. Weber ${ }^{3}$ \\ ${ }^{I}$ Department of Molecular and Medical Pharmacology, David Geffen School of Medicine at UCLA, Los Angeles, California; \\ ${ }^{2}$ Department of Nuclear Medicine, University Hospital Essen, Essen, Germany; and ${ }^{3}$ Molecular Imaging and Therapy Service, \\ Department of Radiology, Memorial Sloan Kettering Cancer Center, New York, New York
}

$\mathbf{T}$ he term theranostics is today perceived as the combination of a predictive biomarker with a therapeutic agent. Use of this term began at the end of the last century and has steadily increased since. A PubMed search for the terms theranostic and theragnostic confirms their increasing popularity (Fig. 1). However, the concept of theranostics is not new to nuclear medicine. In fact, the idea of using a radioactive compound for diagnostic imaging, targetexpression confirmation, and radionuclide therapy dates back to 1946, when Seidlin et al. published the first study on radioiodine therapy for metastatic thyroid cancer (1).

During the last few years there has been unprecedented progress in the field of nuclear theranostics. A phase III randomized, controlled trial provided unequivocal evidence of the remarkable effectiveness of ${ }^{177} \mathrm{Lu}$-DOTATATE for treatment of neuroendocrine tumors (2), and there have been multiple reports of advanced prostate cancer responding dramatically to treatment with radiolabeled ligands targeting prostate-specific membrane antigen (3). These theranostic applications of nuclear medicine in neuroendocrine tumors and prostate cancer have significant economic potential, with a possible yearly revenue of several billion U.S. dollars.

Against the backdrop of these recent successes in nuclear theranostics, this supplement of the Journal of Nuclear Medicine not only offers a detailed overview of the experience with targeted radionuclide therapy in thyroid cancer, neuroendocrine tumors, and prostate cancer but also summarizes other applications of nuclear theranostics, as well as the outlook on new developments. The supplement starts with an article by Levine and Krenning covering the history of theranostics (4). Reubi and Maecke then describe the concept of multireceptor targeting (5). With a special focus on prostate-specific membrane antigen imaging and therapy, the next two articles address strategies for ligand development (6) and how to translate promising preclinical ligands into the clinic (7).

The section on clinical application of theranostics starts with an article dedicated to the best-established and still most frequently used theranostic approach: targeting of the iodine symporter (8). In view of the Food and Drug Administration approval of ${ }^{68} \mathrm{Ga}$-labeled DOTATATE and the soon-expected approval of ${ }^{177} \mathrm{Lu}$-DOTATATE for therapy of well-differentiated neuroendocrine tumors, there are two articles dedicated to the somatostatin receptor: one by Smit Duijzentkunst et al. on somatostatin receptor agonists (9) and one by Fani et al. on somatostatin receptor subtype 2 antagonists (10). Prostate-specific membrane antigen-directed imaging and therapy are covered by Eiber et al.

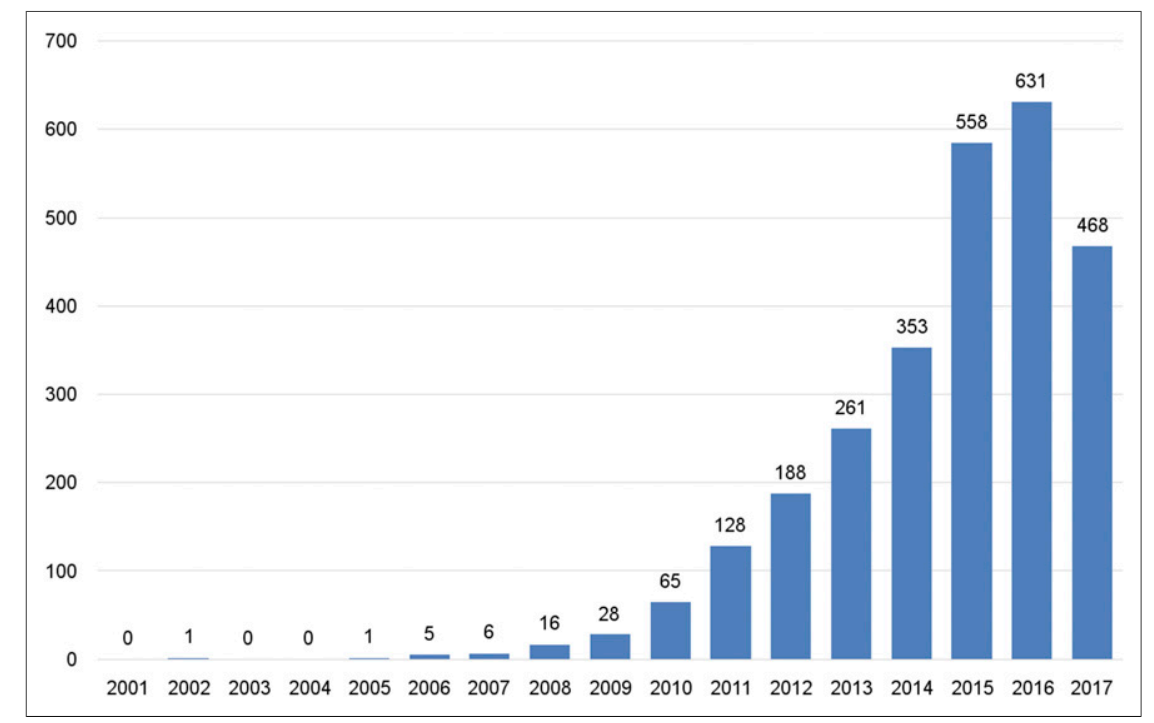

FIGURE 1. PubMed-derived number of publications including the term theranostic or theragnostic during each year from 2001 to 2017 (search performed July 16, 2017).
Received Jul. 20, 2017; accepted Jul. 20, 2017.

For correspondence or reprints contact: Ken Herrmann, Department of Nuclear Medicine, Universitätsklinikum Essen, Hufelandstrasse 55, 200 Medical Plaza, 45147 Essen, Germany.

E-mail: ken.herrmann@uk-essen.de

COPYRIGHT (c) 2017 by the Society of Nuclear Medicine and Molecular Imaging. DOI: 10.2967/jnumed.117.199570
(11), whereas Walenkamp et al. discuss the opportunities and challenges in targeting the chemokine receptor 4 (12). Use of the norepinephrine transporter as a theranostic target is presented by Pandit-Taskar and Modak (13). In addition to the numerous peptide ligands and small molecules, several theranostic antibodies have also been developed; Moek et al. summarize these (14). 
The future dynamics of the field of theranostics are anticipated by one article introducing new radioisotopes (15) and another describing individualized dosimetric concepts (16). The supplement then concludes with an article on intraarterial ${ }^{90} \mathrm{Y}$ therapy of liver metastases (17).

$\mathrm{We}$, the guest editors, are intrigued by the contributions to this supplement by researchers and clinicians known worldwide for their work in theranostics. We believe that theranostics not only is here to stay but represents a unique opportunity for the field of nuclear medicine to grow. We dearly hope that you enjoy this supplement on theranostics as much as we do.

\section{REFERENCES}

1. Seidlin SM, Marinelli LD, Oshry E. Radioactive iodine therapy; effect on functioning metastases of adenocarcinoma of the thyroid. J Am Med Assoc. 1946;132:838-847.

2. Strosberg J, El-Haddad G, Wolin E, et al. Phase 3 trial of ${ }^{177} \mathrm{Lu}$-dotatate for midgut neuroendocrine tumors. N Engl J Med. 2017;376:125-135.

3. Rahbar K, Ahmadzadehfar H, Kratochwil C, et al. German multicenter study investigating ${ }^{177} \mathrm{Lu}-\mathrm{PSMA}-617$ radioligand therapy in advanced prostate cancer patients. J Nucl Med. 2017;58:85-90.

4. Levine R, Krenning EP. Clinical history of the theranostic radionuclide approach to neuroendocrine tumors and other types of cancer: historical review based on an interview of Eric P. Krenning by Rachel Levine. J Nucl Med. 2017;58(suppl 2):3S-9S.

5. Reubi JC, Maecke HR. Approaches to multireceptor targeting: hybrid radioligands, radioligand cocktails, and sequential radioligands. J Nucl Med. 2017; 58(suppl 2):10S-16S.
6. Kopka K, Benešová M, Bařinka C, Haberkorn U, Babich J. Glu-ureido-based inhibitors of prostate-specific membrane antigen: lessons learned during the development of a novel class of low-molecular-weight theranostic radiotracers. J Nucl Med. 2017;58(suppl 2):17S-26S.

7. Haberkorn U, Mier W, Kopka K, Herold-Mende C, Altmann A, Babich J. Identification of ligands and translation to clinical applications. J Nucl Med. 2017; 58(suppl 2):27S-33S.

8. Nagarajah J, Janssen M, Hetkamp P, Jentzen W. Iodine symporter targeting with ${ }^{124} \mathrm{I} /{ }^{131} \mathrm{I}$ theranostics. J Nucl Med. 2017;58(suppl 2):34S-38S.

9. Smit Duijzentkunst DA, Kwekkeboom DJ, Bodei L. Somatostatin receptor 2-targeting compounds. J Nucl Med. 2017;58(suppl 2):54S-60S.

10. Fani M, Nicolas GP, Wild D. Somatostatin receptor antagonists for imaging and therapy. J Nucl Med. 2017;58(suppl 2):61S-66S.

11. Eiber M, Fendler WP, Rowe SP, et al. Prostate-specific membrane antigen ligands for imaging and therapy. J Nucl Med. 2017;58(suppl 2):67S-76S.

12. Walenkamp AME, Lapa C, Herrmann K, Wester H-J. CXCR4 ligands: the next big hit? J Nucl Med. 2017;58(suppl 2):77S-82S.

13. Pandit-Taskar N, Modak S. Norepinephrine transporter as a target for imaging and therapy. J Nucl Med. 2017;58(suppl 2):39S-53S.

14. Moek KL, Giesen D, Kok IC, et al. Theranostics using antibodies and antibodyrelated therapeutics. J Nucl Med. 2017;58(suppl 2):83S-90S.

15. Müller C, van der Meulen NP, Benešová M, Schibli R. Therapeutic radiometals beyond ${ }^{177} \mathrm{Lu}$ and ${ }^{90} \mathrm{Y}$ : production and application of promising $\alpha$-particle, $\beta^{-}$-particle, and auger electron emitters. J Nucl Med. 2017;58(suppl 2): 91S-96S.

16. Eberlein U, Cremonesi M, Lassmann M. Individualized dosimetry for theranostics: necessary, nice to have, or counterproductive? J Nucl Med. 2017; 58(suppl 2):97S-103S.

17. Boas FE, Bodei L, Sofocleous CT. Radioembolization of colorectal liver metastases: indications, technique, and outcomes. J Nucl Med. 2017;58(suppl 2): 104S-111S. 